Gazi University
Journal of Science
$\mathrm{http} / /$ dergipark.gov.tr/gujs

\title{
Effect of Waste Titanium Chips Addition Into the Aluminum Alloys on Their Microstructure
}

\author{
Gokhan OZER ${ }^{1, *(D)}$, Serhat $\mathrm{ACAR}^{2}$ (D) Alptekin KISASOZ ${ }^{3}$ (D) , Kerem Altug GULER ${ }^{2}$ (D) \\ ${ }^{I}$ Fatih Sultan Mehmet Vakif University, Aluminium Test, Training and Research Center (ALUTEAM), TR 34445, Halic Campus, Istanbul, Turkey \\ ${ }^{2}$ Yildiz Technical University, Department of Metallurgical and Materials Engineering, TR 34210, Istanbul, Turkey \\ ${ }^{3}$ Kirklareli University, Faculty of Aeronautics and Space Sciences, TR 39000, Kirklareli, Turkey \\ Highlights \\ - This paper focuses on the recovery of turning chips. \\ - Experimental studies have been carried out with A356 alloy. \\ - Titanium transfer in pure aluminum was found two-fold higher than that of A356.
}

Article Info

Received: 02 Nov 2020

Accepted:10 Feb 2021

Keywords

Aluminum

Titanium

$\mathrm{Al}_{3} \mathrm{Ti}_{\mathrm{TiAl}}$

Turning chips

In-situ composite

\begin{abstract}
In the present study, turning chips were preferred to add titanium into liquid aluminum. Although being easy to reach and cheap, the chips were thought to be effective in minor titanium addition with their large surface area. Experimental studies have been carried out with A356 casting alloy and commercial purity aluminum. The effects of different process parameters were investigated on titanium transfer efficiency, microstructural and microhardness properties of the formed phases. The processes were carried out between $740-820^{\circ} \mathrm{C}$, for 2,4 , and $6 \mathrm{~h}$, with the amount of added chips 5 and 10 wt.\% ( 3 and 6 vol.\%). The experiments were conducted with both commercially pure $\mathrm{Al}$ and $\mathrm{A} 356$ alloy. The microstructural investigations and microhardness measurements were carried out on the formed $\mathrm{Al}_{3} \mathrm{Ti}$ and $(\mathrm{Al}, \mathrm{Si})_{3} \mathrm{Ti}$ phases. The first noticeable result was that titanium transfer was more efficient in pure aluminum than in the A356 alloy. Also, it was observed that this difference became more significant with an increase in wt.\% addition. The measured microhardness values were also differentiated depending on the $\mathrm{Si}$ content of the formed $\mathrm{Al}_{3} \mathrm{Ti}$ compound. Due to the presence of high Si content in A356 alloy, transference efficiencies of $\mathrm{Ti}$ were found highly limited compared to pure aluminum as the silicon enrichment in the $\mathrm{Al}_{3} \mathrm{Ti}$ compound reduces the diffusion of titanium and the growth rate of $\mathrm{Al}_{3} \mathrm{Ti}$ particles. Maximum transference efficiency was found $47.05 \%$ with $10 \%$ wt. chip addition in commercially pure aluminum at the processing conditions of $780{ }^{\circ} \mathrm{C}$ for $4 \mathrm{~h}$.
\end{abstract}

\section{INTRODUCTION}

Aluminum alloys have been used in the automotive and aerospace industries for over 80 years because of their outstanding properties such as good ductility, specific strength, corrosion resistance, availability, and relatively low cost [1-3]. In the past several decades, ceramic reinforced aluminum matrix composites (AMCs) have been in the spotlight due to their superior mechanical properties [4,5]. On the other hand, thermal and crystallographic incompatibility issues may limit the employment of ceramic reinforcements. In order to overcome these obstacles, the employment of intermetallic particles with better wettability and strong interfacial bonding with the matrix instead of conventional ceramic particles is one of the most prominent routes for reinforcement of $\mathrm{Al}$ alloys $[6,7]$. Intermetallics like $\mathrm{Al}_{3} \mathrm{Ti}$, have lower brittleness and close coefficient of thermal expansion (CTE) to aluminum compared to the conventional ceramic components, and they also provide low density, high resistance to oxidation and corrosion, and high strength $[8,9]$. These properties make $\mathrm{Al}_{3} \mathrm{Ti}$ intermetallic a competent alternative for light structural applications [10]. 
The efforts on reinforcing $\mathrm{Al}$ alloys with intermetallic particles are concentrated on two different approaches; solid-state and liquid state routes. The solid-state processing routes are mainly based on powder metallurgy (PM), mechanical alloying, and friction stir [11,12] techniques. Although the mechanical properties obtained in the mentioned studies are promising, the reaction rate in the solid phase is quite low. Therefore, the full transformation of the solid particles into the composite is complicated [13].

In the liquid state routes, the reinforcement phase is usually generated via in-situ processing techniques where the reinforcement particles are formed via exothermic reactions within the molten matrix alloy. This approach has been considered by many researchers due to its low cost, high efficiency, and more stable interface properties [14]. $\mathrm{Al}_{3} \mathrm{Ti}$ reinforced $\mathrm{Al}$ composites by in-situ reaction of molten 6061 aluminum with $\mathrm{K}_{2} \mathrm{TiF}_{6}$. The resulting reaction between the salt and aluminum was given as:

$3 K_{2} T i F_{6}+13 A l=3 A l_{3} T i+K_{3} A l F_{6}+3 K_{A l F_{4}}$.

They also employed ultrasonic melt treatment to ensure the refinement of the microstructure and better particle dispersion. According to their findings, the $\mathrm{Al}_{3} \mathrm{Ti}$ particles promoted heterogeneous nucleation and caused even finer microstructure. The reinforcement of the 6061 matrix with Al3Ti significantly improved the tensile properties of the alloy, and the thermal mismatch strengthening was reported as the dominant strengthening mechanism.

Before experiments also utilized $\mathrm{K}_{2} \mathrm{TiF}_{6}$ salt-metal reactions to produce 5 vol. \% $\mathrm{Al}_{3} \mathrm{Ti} / \mathrm{A} 356$ composites [15]. They also investigated the effects of T6 heat treatment and Sr modification on the microstructural and mechanical properties of the composites. According to their conclusions, the $\mathrm{Al}_{3} \mathrm{Ti}$ particles formed with a blocky morphology with an average size of 5-6 $\mu \mathrm{m}$. The existence of $\mathrm{Al}_{3}$ Ti particles restricted the growth of eutectic Si particles in as-cast specimens. They also observed that in the as-cast composites, the Si element might substitute $\mathrm{Al}$ in the $\mathrm{Al}_{3} \mathrm{Ti}$ particulates. A significant increase in the yield strength was reported by 5 vol. \% in-situ composites for both as-cast and T6 treated samples.

It is reported that the employment of fluorotitanates may hinder the interaction between liquid aluminum and the formed particulates because the fluorides formed during the reactions may surround the reinforcing particles. Chen et al. [16] employed titanium powder and cryolite salt to produce 7075 matrix composites with different weight percentages of $\mathrm{Al}_{3} \mathrm{Ti}$ particles by in situ stir casting process. They observed good distribution of the particles with low Ti contents, fine and equiaxed grain morphology with $1 \mathrm{wt}-\% \mathrm{Ti}$ added specimen. They also reported a significant improvement in the strength when $1 \mathrm{wt}-\% \mathrm{Ti}$ was added. However, a further increase in the Ti content resulted in a decrease in strength and ductility values.

Another different approach was employed by Liu et al. [17] for fabricating $\mathrm{Al}_{3} \mathrm{Ti} / \mathrm{Al}$ composites with the ultrasound-assisted in situ casting via a direct reaction between the Ti powders and the liquid aluminum. In that study, Ti powders with $\% 99.7$ purity were added into the molten $\mathrm{Al}$ at $780{ }^{\circ} \mathrm{C}$ with also $\% 99.7$ purity. The researchers targeted Al-10wt. \% Ti composites via given reaction below

$3 A l+T i=\mathrm{Al}_{3} \mathrm{Ti}$.

According to their observations, $\mathrm{Al}_{3} \mathrm{Ti}$ particles occurred in blocky morphology with an average size of 5 $\mu \mathrm{m}$, and high-intensity ultrasonic vibration may lead to the uniform distribution of the reinforcing particles. It can accelerate the reaction process between the solid powders and the liquid Al.

For the addition of titanium content into aluminum alloys, waste chips can be a good alternative. It can be said that it has advantages compared to the use of salt. Because magnesium fluoride $\left(\mathrm{MgF}_{2}\right)$ by-product is formed as a result of the use of $\mathrm{K}_{2} \mathrm{TiF}_{6}$ salt, causing the magnesium in the alloy to decrease. Besides, titanium chips are available at a much lower cost and in many different thicknesses and lengths than master alloys or powder products.

In the present work, turning scraps, a kind of waste material, were used to add titanium to the molten aluminum. The primary impulse was that with their large surface area, the scraps are thought to cause direct reaction with high efficiency. Besides they are cheap and available. In this study, titanium scraps were introduced in A356 aluminum alloy and commercially pure aluminum at different temperatures (varied between 740 and $820{ }^{\circ} \mathrm{C}$ ), with varying amounts (5 and 10 wt. \%), and with different durations of the 
process (varied between 2 and 6 hours). The effects of the process parameters on the chemical compositions, microstructural properties, and microhardness values were discussed.

\section{MATERIAL METHOD}

In our study, turning chips obtained from a $20 \mathrm{~mm}$ diameter rod with commercial purity were used as a source of titanium. The experimental process started with the A356 casting alloy and then continued with commercially pure aluminum. The chemical compositions of these two materials and the employed commercially pure titanium are given in Table 1 .

Table 1. Chemical compositions of A356 alloy, commercial purity aluminum ingots, and titanium chips

\begin{tabular}{|l|c|c|c|c|c|c|c|c|c|c|c|}
\hline Alloy & $\mathrm{Si}$ & $\mathrm{Fe}$ & $\mathrm{Cu}$ & $\mathrm{Mn}$ & $\mathrm{Mg}$ & $\mathrm{Zn}$ & $\mathrm{Ni}$ & $\mathrm{Ti}$ & $\mathrm{Pb}$ & $\mathrm{O}$ & $\mathrm{Al}$ \\
\hline A356 & 7.288 & 0.144 & 0.011 & 0.028 & 0.354 & 0.008 & 0.0031 & 0.123 & 0.0117 & & Bal. \\
\hline CPAl & 0.083 & 0.234 & - & - & 0.005 & 0.008 & - & 0.005 & - & & Bal. \\
\hline CP Ti & - & 0.265 & - & - & - & - & - & 99.555 & - & 0.180 & - \\
\hline
\end{tabular}

Approximately $350 \mathrm{~g}$ of metal was melted in each experiment, and the amount of titanium to be added was calculated regarding the exact weight of the charged aluminum. The addition of titanium was made by preheating at about $200{ }^{\circ} \mathrm{C}$ after the aluminum alloy had wholly melted and reached the processing temperature. Since the efficiency of this process was unknown, related percentages were determined arbitrarily. Unfortunately, an efficient casting process could not be achieved by $15 \%$ wt. addition as the amount of the chips increased it became harder to embed them within the liquid metal. Therefore, only two different levels could be tested. Sample production was carried out by pouring the liquid metal into a 30 $\mathrm{mm}$ diameter steel mold at the end of the process. Before the metal was poured, slag was removed from the surface, and the soft viscous residue left at the bottom of the ladle was prevented from flowing into the mold. Pieces of small cast ingots were cut, and chemical compositions were determined by optical emission spectrometer analysis, and titanium amounts were determined. Samples produced depending on the process variables and their titanium contents, titanium transfer rate, and efficiency are shown in Table 2.

Table 2. Experimental process parameters and titanium transfer data

\begin{tabular}{|l|c|c|c|c|c|c|}
\hline $\begin{array}{l}\text { Sample } \\
\text { No. }\end{array}$ & Alloy & $\begin{array}{c}\text { Process } \\
\text { Temp. } \\
\left({ }^{\circ} \mathrm{C}\right)\end{array}$ & $\begin{array}{c}\text { Process } \\
\text { Duration } \\
(\mathrm{h})\end{array}$ & $\begin{array}{c}\text { Ti addition } \\
(\text { wt \%) }\end{array}$ & $\begin{array}{c}\text { Ti in } \\
\text { casting (wt } \\
\%)\end{array}$ & $\begin{array}{c}\text { Ti transference } \\
\text { efficiency }(\%)\end{array}$ \\
\hline 1 & A356 & 780 & 4 & 5 & 0.770 & 12.94 \\
\hline 2 & A356 & 820 & 4 & 5 & 0.741 & 12.36 \\
\hline 3 & A356 & 740 & 4 & 5 & 0.728 & 12.10 \\
\hline 4 & A356 & 780 & 4 & 5 (rod) & 0.178 & 1.10 \\
\hline 5 & A356 & 780 & 4 & 10 & 2.430 & 23.07 \\
\hline 6 & A356 & 780 & 4 & 5 & 0.434 & 6.22 \\
\hline 7 & C.P. & 780 & 4 & 5 & 0.805 & 16.00 \\
\hline 8 & C.P. & 780 & 4 & 10 & 4.710 & 47.05 \\
\hline 9 & C.P. & 820 & 4 & 10 & 4.610 & 46.05 \\
\hline 10 & C.P. & 780 & 6 & 10 & 2.750 & 27.45 \\
\hline 11 & C.P. & 780 & 2 & 10 & 2.850 & 28.45 \\
\hline
\end{tabular}

The transference efficiencies were calculated by subtracting the initial amount of Ti measured in the employed A356 alloy and CP aluminum (can be seen in Table 1), and then these values were rated to the amount of added titanium, and the obtained values are given in percentages. Titanium turning chips were used in all experiments except Sample No. 4, and the average thickness of the chips was $0.1 \mathrm{~mm}$. In Sample No. 4 , a cut piece (rod-shaped bulk) from which the chips were obtained was added to the liquid metal. 
Unlike the others, mechanical vibration was applied in the production of Sample No. 6. In that trial, at the end of the second hour and just before casting, the crucible was taken from the furnace (Protherm PLF 130/25) and placed in the vibration device (Octagon 200), and vibrated for four minutes with a frequency of $50 \mathrm{~Hz}$ and $1.8 \mathrm{~mm}$ amplitude. The images of the vibration system and the employed mold are given in Figure 1.
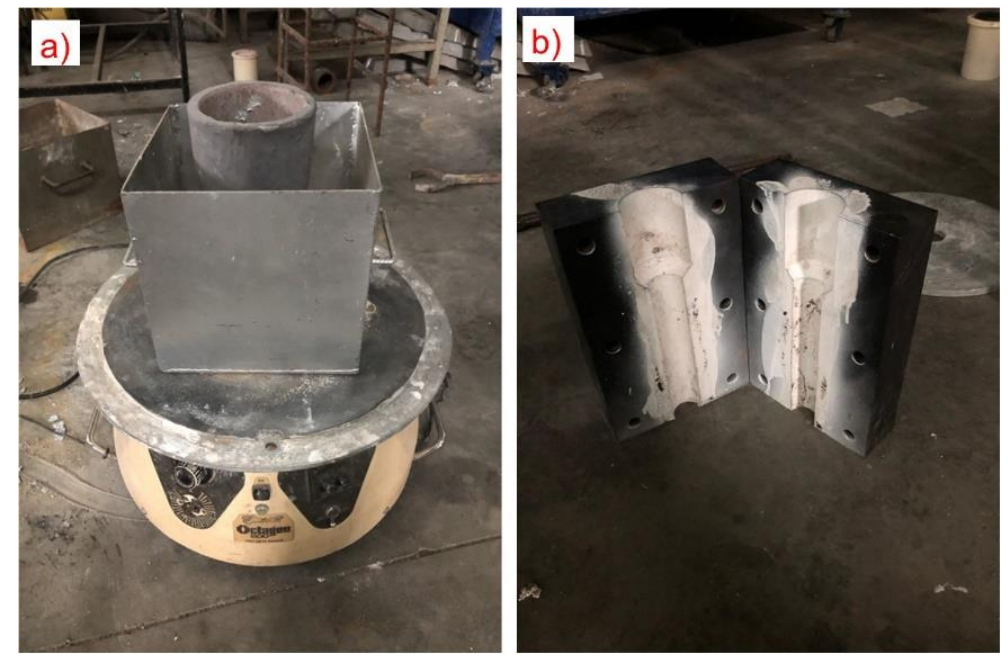

Figure 1. The images of; a) vibration system, b) employed steel mold

During the characterization phase, samples were ground up to 2000 grit and polished mechanically with 1 $\mu \mathrm{m}$ diamond suspension. Microstructures of the specimens were examined at polished state via light microscopy (NIKON Eclipse MA 100) and Scanning Electron Microscope (SEM-HITACHI SU 3500). Energy Dispersive X-Ray Spectroscopy (EDS) point and mapping analyzes were also carried out for selected specimens. Furthermore, microhardness measurements (HV0.1) (SHIMADZU G21D) were carried out on obtained intermetallic phases.

\section{THE RESEARCH FINDINGS AND DISCUSSION}

As can be seen in Table $2,780^{\circ} \mathrm{C} / 4 \mathrm{~h}$ operation conditions were determined as the main process parameters in the study. Although $820^{\circ} \mathrm{C}$ is a relatively high temperature for aluminum melting, this temperature was also tested in both A356 and commercial pure aluminum. Such an increase in the melting temperature was not found to improve titanium transfer. In addition, in this high-temperature processing of A356 alloy, the loss of $\mathrm{Mg}$ element in the melt increased significantly and measured $\mathrm{Mg}$ content was below $0.2 \%$. Longterm processes at high temperatures cause a reduction of reactive alloying elements such as $\mathrm{Mg}$ that can be oxidized quickly and easily. A356 is an alloy that can be hardened by precipitation hardening, and it has this feature thanks to its small amount of $\mathrm{Mg}$. The very low amount of $\mathrm{Mg}$ will have a harmful effect on the hardenability and the strength of the alloy. Therefore, when working with alloys such as A356, it is necessary to avoid high processing temperatures and prolonged processing times, or the reduced amount of reactive elements must be compensated.

Although the titanium transfer is slightly below in the process performed at $740{ }^{\circ} \mathrm{C}$, it is quite close to 780 ${ }^{\circ} \mathrm{C}$. When solid titanium is added to the liquid aluminum, titanium transfer occurs mainly as the formation of the $\mathrm{Al}_{3} \mathrm{Ti}$ intermetallic compound. The absence of significant differences between the titanium transferred according to the tested temperatures indicates that $\mathrm{Al}_{3} \mathrm{Ti}$ formation is not very sensitive to this temperature range.

The importance of the surface area and section thickness in a diffusion-based process is undeniable. In order to see this effect and reveal the difference in quantity, the rod-shaped Ti additive was used instead of chips in Sample No. 4. In this sample, the titanium transfer efficiency has dropped more than ten times compared to the sample employed sawdust. While it seems theoretically possible to dissolve all of the titanium added to the liquid aluminum, a certain part of it could be transferred during the process. It was understood from the residue left in the crucible during casting, and also the quantities transferred were 
measured for spectrometer analysis that the employed amount of titanium could not be diffused in a full manner.

The amount of transferred titanium increased with the increase in the amount of titanium added as expected. However, it has been demonstrated that there is no linearity in the amount transferred. The transfer efficiency in experiments with a 5\% contribution was found $12 \%$ in A356 alloy, while it was $16 \%$ in pure aluminum. On the other hand, the $10 \%$ addition yielded over $23 \%$ transfer efficiency in the A356 alloy, and it reached $47 \%$ in pure aluminum, which was the highest transfer efficiency value achieved.

Figure 2 a, b, and c, microstructure images of Sample No. 1, 5, and 8 are given, respectively. Taking advantage of the density difference, BSE Comp. images were taken to see $\mathrm{Al}_{3} \mathrm{Ti}$ particles clearly. In the microstructure of the samples cast with 5\% $\mathrm{Ti}$ additive, $\mathrm{Al}_{3} \mathrm{Ti}$ particles are seen in anount that is proportional to the transfer rate. Some of these particles are polygonal, and most of them are needle-shaped. In the samples with $10 \% \mathrm{Ti}$ scrap additive, an image that can be characterized as an in-situ composite with the $\mathrm{Al}_{3} \mathrm{Ti}$ particles scattered throughout the structure, especially in pure aluminum, has emerged. While the $\mathrm{Al}_{3} \mathrm{Ti}$ compound in low titanium content is formed in needle form, polygonal shape formation became dominant with the increase in the titanium ratio. The possible explanation for this morphological differentiation is that as the amount of the formed $\mathrm{Al}_{3} \mathrm{Ti}$ particles increases, they tend to agglomerate with each other within polyhedral morphology.
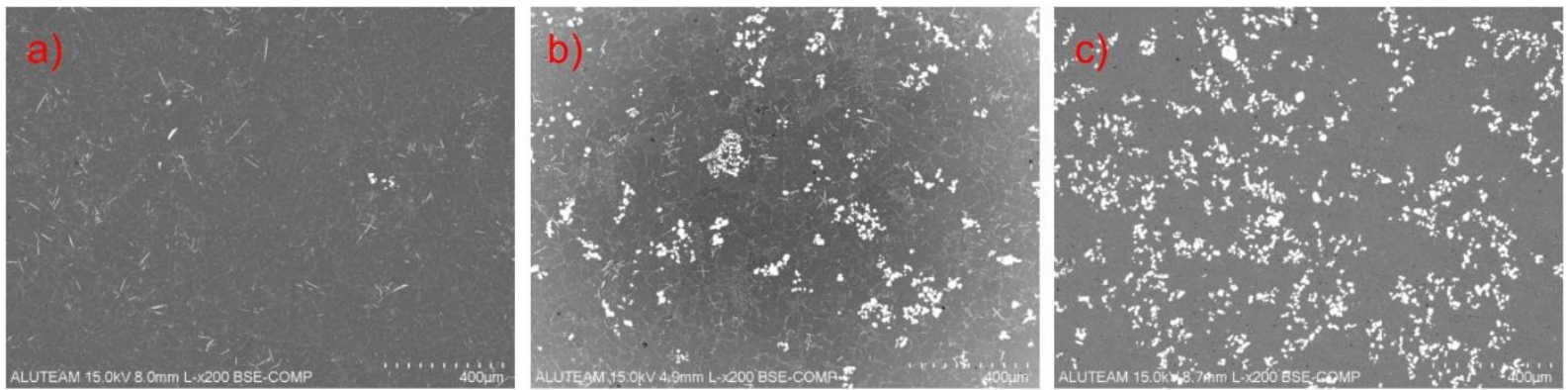

Figure 2. Microstructure SEM images of; a) Sample No. 1, b) Sample No. 5, c) Sample No. 8

When solid titanium is added to the liquid aluminum, $\mathrm{Al}_{3} \mathrm{Ti}$ formation begins with nucleation on the liquidsolid interface. Following the growth of nuclei, these particles separate from the interface and mix in the liquid. In the light microscope image taken from Sample No. 5 given in Figure 3, this formation can be clearly seen around a chip particle inside the structure. Liu and his friends also named this mechanism as a reaction-peeling model in their in-situ composites by adding titanium powder to liquid aluminum and explained it in detail [17].

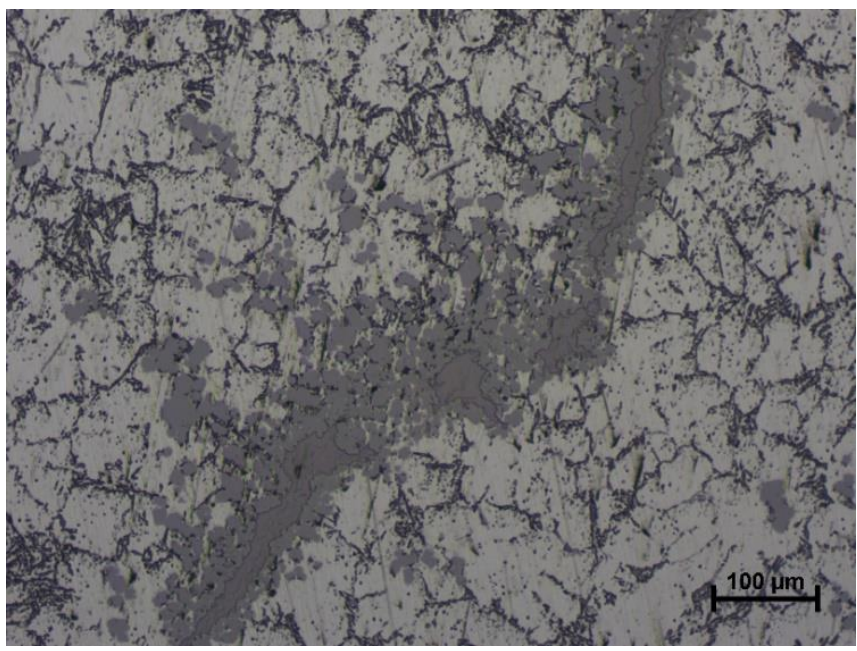

Figure 3. Optical microscope image of Sample No. 5 
There is a difference between titanium transfer efficiencies between the A356 alloy and pure aluminum. This difference became evident $10 \%$ chip addition. A356 is a casting alloy containing a large amount of Si. In the presence of silicon $\mathrm{Al}_{3} \mathrm{Ti}$ compound can dissolve up to $10-11 \% \mathrm{Si}$ as contained in aluminum, and in this case, it is also called ( $\mathrm{Al}, \mathrm{Si})_{3} \mathrm{Ti}$ compound. In their in-situ composite study by using the A356 alloy and $\mathrm{K}_{2} \mathrm{TiF}_{6}$ salt pair, Yang et al. explained that $\mathrm{Si}$ atoms are included in the $\mathrm{Al}_{3} \mathrm{Ti}$ compound as a substitute for $\mathrm{Al}$ atoms and preferred in terms of formation energy [18]. Silicon enrichment in the $\mathrm{Al}_{3} \mathrm{Ti}$ compound reduces the diffusion rate of titanium and reduces the growth rate of $\mathrm{Al}_{3} \mathrm{Ti}$ particles.

The difference between the compounds was determined by EDS analysis in SEM examinations and given in Figure 4 and Figure 5. In the EDS mapping analysis, it is seen that the intermetallic phase formed in Sample No. 8 is composed of $\mathrm{Al}$ and Ti elements (Figure 4). In comparison, Sample No. 5 has a Si element in the intermetallic phase (Figure 5).

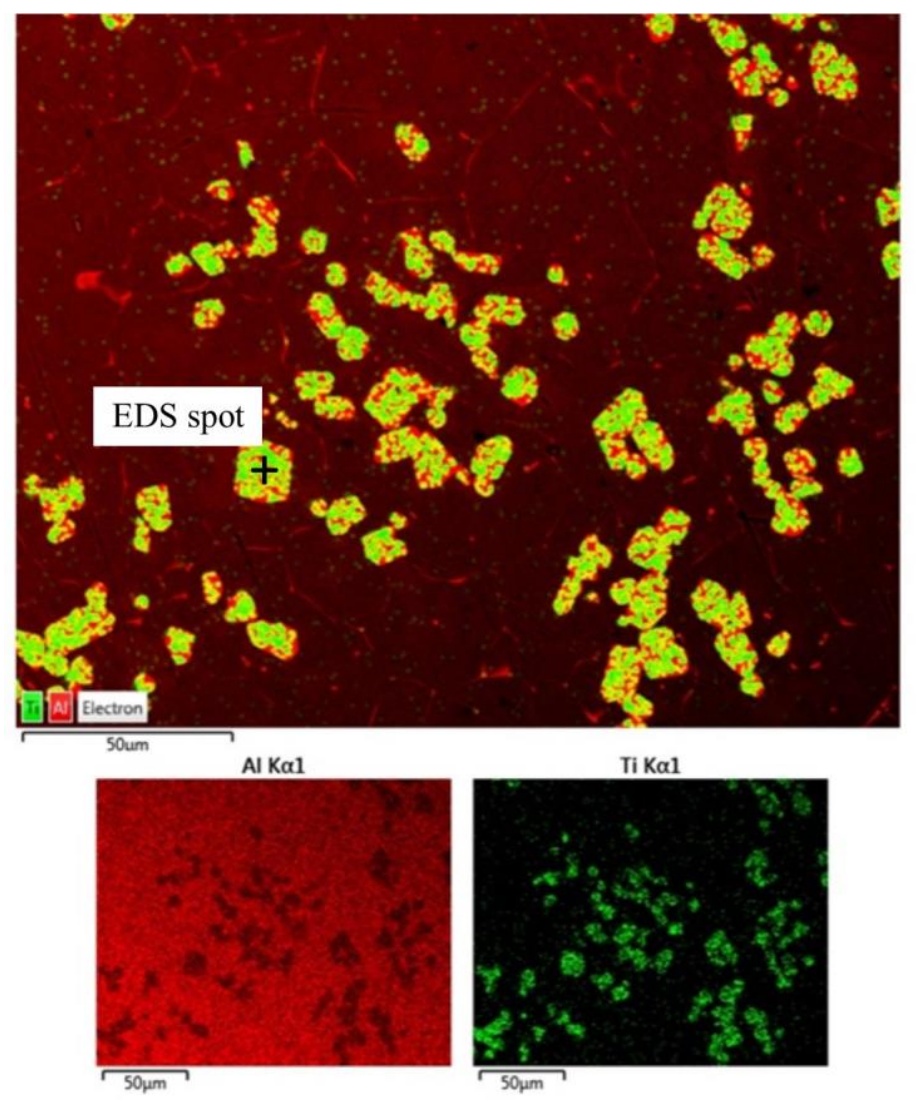

Figure 4. EDS mapping analysis of Sample No. 8 


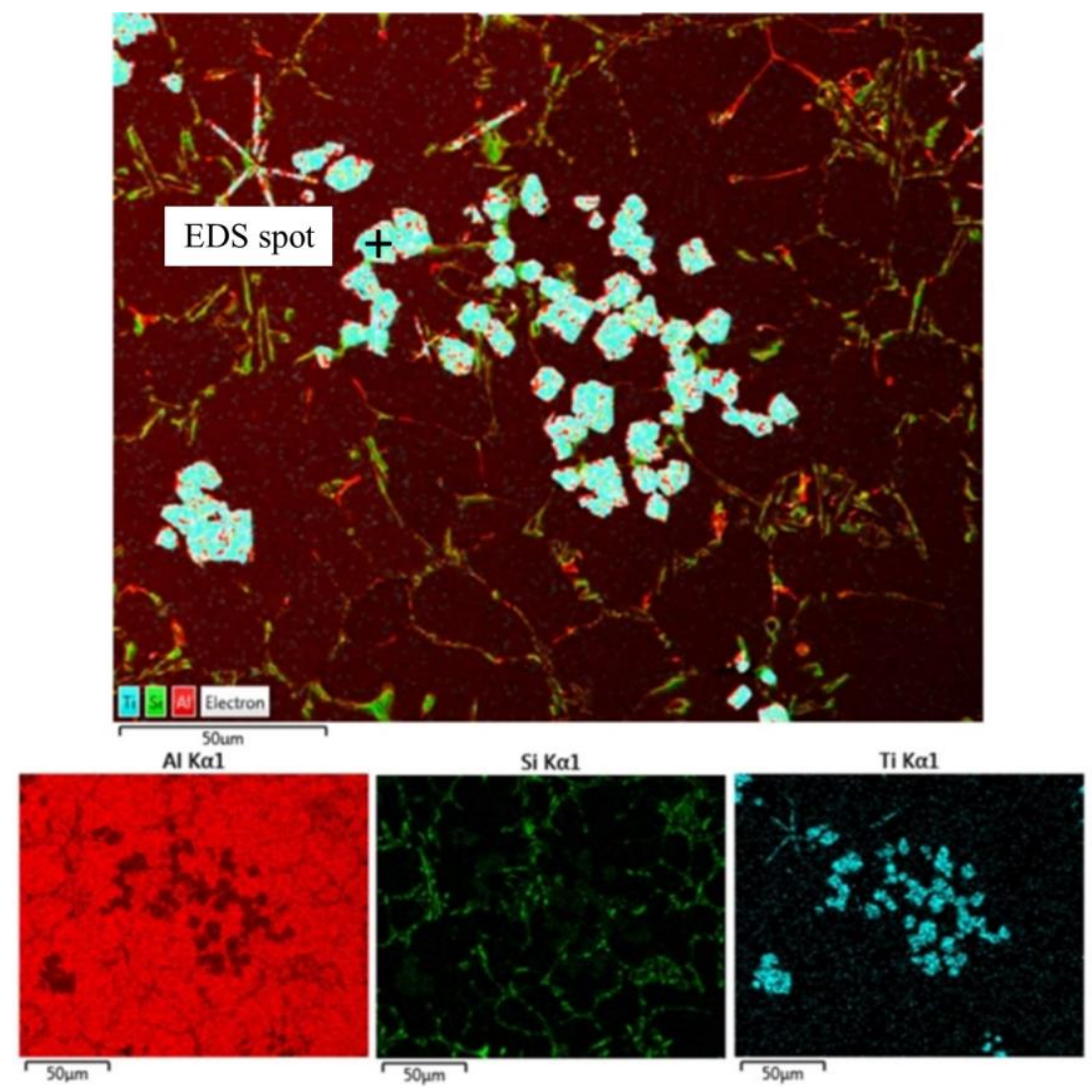

Figure 5. EDS mapping analysis of Sample No. 5

In EDS point analysis, $\mathrm{Al}_{3} \mathrm{Ti}$ compounds in Sample No. 5 were found to contain a significant amount of $\mathrm{Si}$, and results are given in Figure 6.

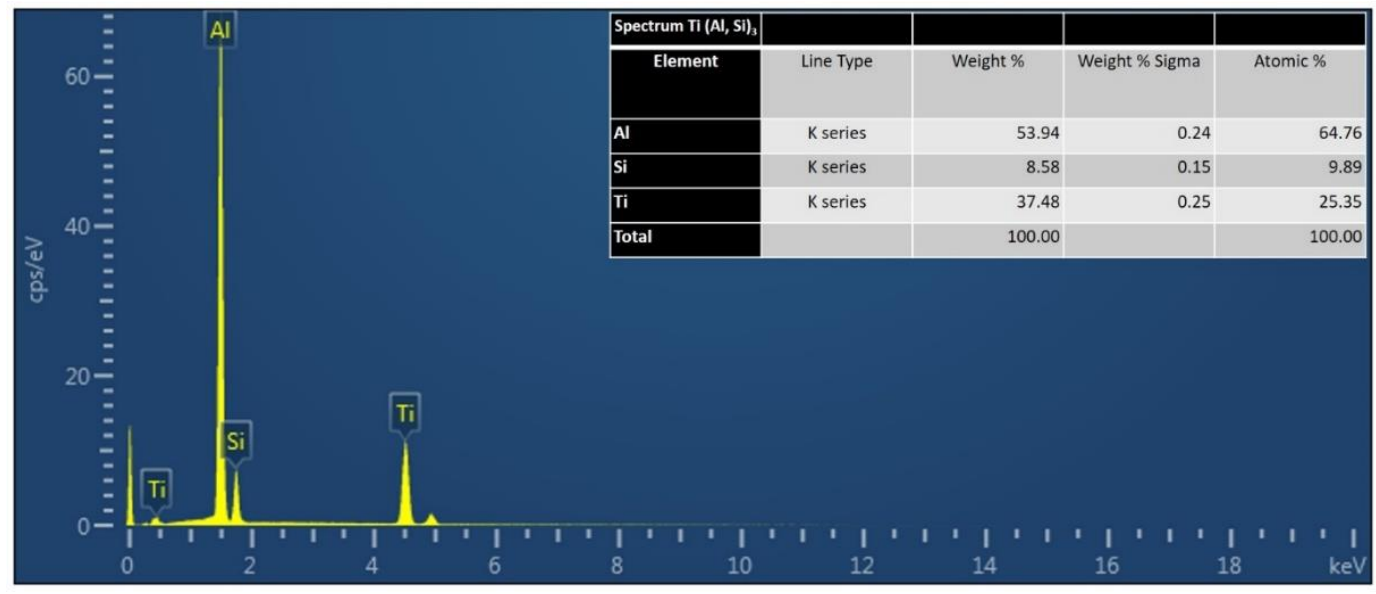

Figure 6. EDS point analysis results in the intermetallic phase of Sample No. 5

A factor that may be effective in the resulting higher transfer of Ti in pure aluminum than the A356 alloy is the difference between the viscosities of these two alloys in liquid form at the same temperature. The A356 alloy is known for its high Si ratio and good fluidity. Pure aluminum in liquid form is well-known for its low fluidity. According to Stokes law, $\mathrm{Al}_{3} \mathrm{Ti}$ particles should have a higher rate of agglomeration in A356 alloy than the pure aluminum. In this case, it will be easier for the particles to move away from the liquid and hence the poured ingots.

In the EDS point analysis performed in the intermetallic phase of Sample No. 8, only the $\mathrm{Al}$ and Ti elements are present, and their rates are shown in Figure 7. 


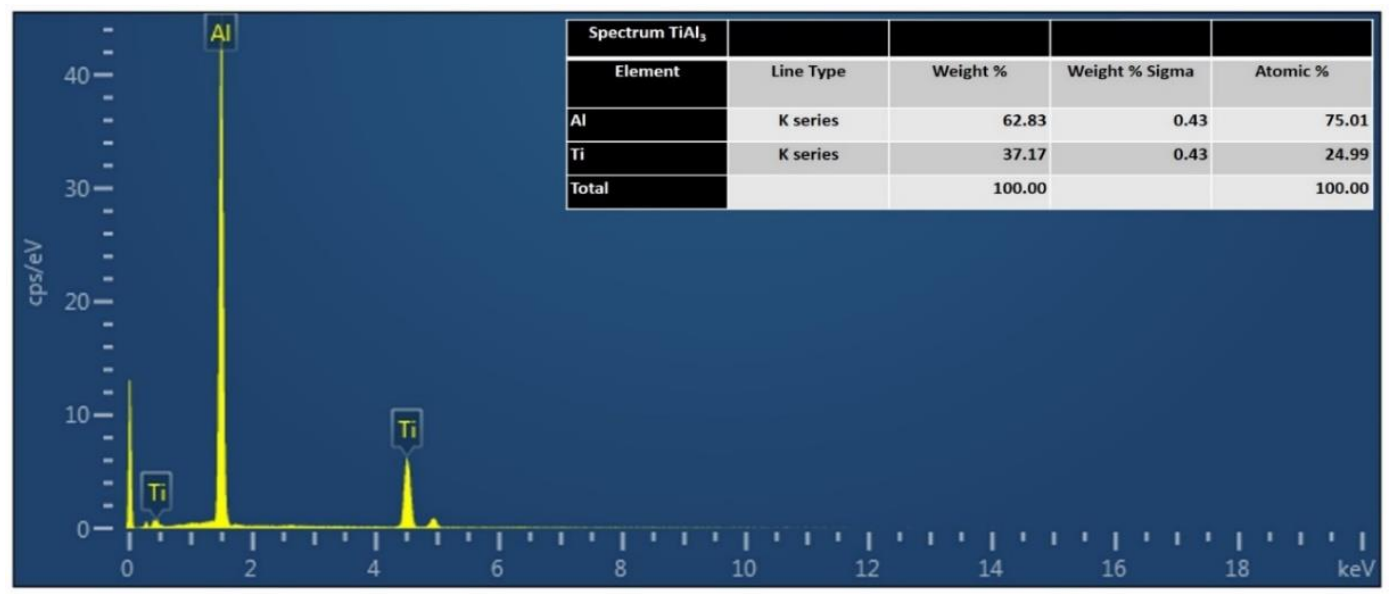

Figure 7. EDS point analysis results in the intermetallic phase of Sample No. 8

In Sample No. 6, the vibration was applied with the idea that it can distribute the accumulation in the Al/Ti interface into the liquid and accelerate the diffusion and reaction. However, it has been found that the vibration dramatically reduces the titanium transfer amount and efficiency rather than increasing it. Even though mechanical vibration disperses $\mathrm{Al}_{3} \mathrm{Ti}$ particles in the boundary layer, it has also allowed them to move away from the liquid, possibly causing agglomeration.

The effect of the change in the processing time was investigated in Sample No. 10 and 11. The prolongation of the process from 2 hours to 4 hours increased the amount of titanium transfer, while the extension from 4 hours to 6 hours decreased it to almost the same level as 2 hours. As these results show, the amount of titanium in liquid aluminum does not constantly increase with increased process duration. The $\mathrm{Al}_{3} \mathrm{Ti}$ particles formed by the prolongation of the process may be agglomerated and sank to the bottom of the crucible.

The wide range of size distribution of polygonal $\mathrm{Al}_{3} \mathrm{Ti}$ particles in microstructure images shows that these particles have a high tendency to agglomerate. In Figure 8 a and b, it is remarkable that a relatively high magnification optical microscope and SEM images, taken from Sample No. 5 and 8, have many nodes (neck) between $\mathrm{Al}_{3} \mathrm{Ti}$ particles. The density of $\mathrm{Al}_{3} \mathrm{Ti}$ particles is significantly higher than the density of aluminum, with a value of $3.36 \mathrm{~g} / \mathrm{cm}^{3}$, which also affects the agglomeration rate.

In the sample produced with commercial pure aluminum and titanium chips (Sample No. 8), the microhardness value of the $\mathrm{Al}_{3} \mathrm{Ti}$ compound was measured on average $565 \mathrm{HV} 0.1$; while in the sample produced with A356 alloy (Sample No. 5), the microhardness value increased to $680 \mathrm{HV} 0.1$ on average in case of $(\mathrm{Al}, \mathrm{Si})_{3} \mathrm{Ti}$ formation. The introduction of silicon atoms into the $\mathrm{Al}_{3} \mathrm{Ti}$ lattice resulted in increased hardness.
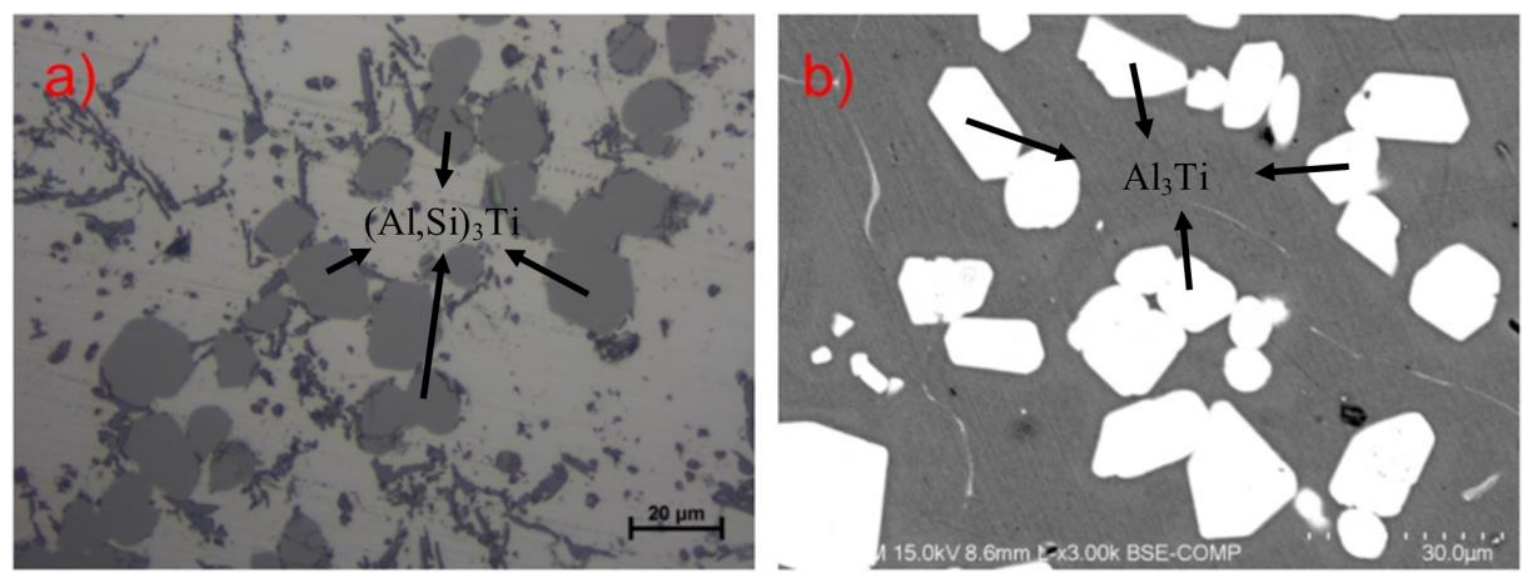

Figure 8. a) Optical microstructure of the Sample No. 5 (500 X magnification), b) SEM microstructure of the Sample No. 8 


\section{CONCLUSIONS}

In this research, it was tried to determine the characteristics of using titanium chips, which is waste material, and being able to participate in liquid aluminum. Particular emphasis is placed on the elemental transfer of titanium and its efficiency. Titanium transfer in pure aluminum was found about two times higher than that of A356 alloy with $10 \mathrm{wt} . \%$ turning chip addition at the processing conditions of $780{ }^{\circ} \mathrm{C}$ and $4 \mathrm{~h}$. The effects of silicon entering the $\mathrm{Al}_{3} \mathrm{Ti}$ compound and increasing fluidity are reflected in titanium transfer. While it was observed that the $\mathrm{Al}_{3} \mathrm{Ti}$ compound mostly formed in needle form in low titanium content, polygonal shape formation dominated by a high titanium ratio, it has been observed that vibration does not always show the expected effect, and duration is one of the most effective parameters. It was determined that the titanium transfer dropped to almost two hours level after six hours process. With their large surface area, chips were much more efficient in transferring than the bulk material. Maximum transference efficiency was calculated as $47.05 \%$ with $10 \%$ wt. chip addition in commercially pure aluminum at the processing conditions of $780{ }^{\circ} \mathrm{C}$ for $4 \mathrm{~h}$. The microhardness values of the formed $\mathrm{Al}_{3} \mathrm{Ti}$ phase increased about $\% 20$ by the employment of A356 alloy with the dissolution of the Si atoms in the intermetallic compound. However, there was no morphological difference between $\mathrm{Al}_{3} \mathrm{Ti}$ and $(\mathrm{Al}, \mathrm{Si})_{3} \mathrm{Ti}$ intermetallic.

\section{CONFLICTS OF INTEREST}

No conflict of interest was declared by the authors.

\section{REFERENCES}

[1] Hirsch, J., "Recent development in aluminium for automotive applications", Transactions of Nonferrous Metals Society of China, 24: 1995-2002, (2014).

[2] Dursun, T., Soutis, C., "Recent developments in advanced aircraft aluminium alloys", Materials \& Design (1980-2015), 56: 862-871, (2014).

[3] Habibolahzadeh, A., Hassani, A., Bagherpour, E., Taheri, M., "Dry friction and wear behavior of in-situ Al/Al3Ti composite", Journal of Composite Materials, 48: 1049-1059, (2014).

[4] Wang, K., Li, W., Du, J., Tang, P., Chen, J., "Preparation, thermal analysis and mechanical properties of in-situ $\mathrm{Al} 2 \mathrm{O} 3 / \mathrm{SiO} 2(\mathrm{p}) / \mathrm{Al}$ composites fabricated by using zircon tailing sand", Materials \& Design, 99: 303-313, (2016).

[5] Chao, Z. L., Zhang, L. C., Jiang, L. T., Qiao, J., Xu, Z. G., Chi, H. T., Wu, G.H., "Design, microstructure and high temperature properties of in-situ $\mathrm{Al} 3 \mathrm{Ti}$ and nano-Al2O3 reinforced 2024Al matrix composites from Al-TiO2 system”, Journal of Alloys and Compounds, 775: 290297, (2019).

[6] Ahmadvand, M. S., Azarniya, A., Madaah, H. R., "Thermomechanical synthesis of hybrid in-situ $\mathrm{Al}-(\mathrm{Al} 3 \mathrm{Ti}+\mathrm{Al} 2 \mathrm{O} 3)$ composites through nanoscale Al-A12TiO5 reactive system", Journal of Alloys and Compounds, 789: 493-505, (2019).

[7] Azarniya, A., Taheri, A. K., Taheri, K. K., "Recent advances in ageing of 7xxx series aluminum alloys: A physical metallurgy perspective", Journal of Alloys and Compounds, 781: 945-983, (2019).

[8] Ma, S., Zhuang, X., Wang, X., "3D micromechanical simulation of the mechanical behavior of an in-situ A13Ti/A356 composite", Composites Part B: Engineering, 176: 107-115, (2019). 
[9] Tochaee, E. B., Madaah, H. R., Reihani, S. M., "Fabrication of high strength in-situ Al-Al3Ti nanocomposite by mechanical alloying and hot extrusion: Investigation of fracture toughness", Materials Science and Engineering: A, 658: 246-254, (2016).

[10] Guo, B., Ni, S., Shen, R., Song, M., "Fabrication of Ti-Al 3 Ti core-shell structured particle reinforced Al based composite with promising mechanical properties", Materials Science and Engineering: A, 639: 269-273, (2015).

[11] Zhang, Q., Xiao, B. L., Wang, D., Ma, Z. Y., "Formation mechanism of in situ Al3Ti in Al matrix during hot pressing and subsequent friction stir processing", Materials Chemistry and Physics, 130: 1109-1117, (2011).

[12] Hsu, C. J., Chang, C. Y., Kao, P. W., Ho, N. J., Chang, C. P., “Al-Al3Ti nanocomposites produced in situ by friction stir processing", Acta Materialia, 54: 5241-5249, (2006).

[13] Chatterjee, S., Ghosh, A., Basu, M. A., "Understanding the evolution of microstructural features in the in-situ intermetallic phase reinforced Al/Al3Ti nanocomposite", Materials Today: Proceedings, 5: 10118-10130, (2018).

[14] Gupta, R., Chaudhari, G. P., Daniel, B. S. S., "Strengthening mechanisms in ultrasonically processed aluminium matrix composite with in-situ Al3Ti by salt addition", Composites Part B Engineering, 140: 27-34, (2018).

[15] Zeng, Y., Himmler, D., Randelzhofer, P., Körner, C., "Microstructures and Mechanical Properties of Al3Ti/Al Composites Produced In Situ by High Shearing Technology", Advanced Engineering Materials, 21: 1-10, (2019).

[16] Chen, X. H., Yan, H., Jie, X. P., "Effects of ti addition on microstructure and mechanical properties of 7075 alloy", International Journal of Cast Metals Research, 28: 151-157, (2015).

[17] Liu, Z., Han, Q., Li, J., "Fabrication of in situ Al3Ti/Al composites by using ultrasound assisted direct reaction between solid Ti powders and liquid Al", Powder Technology, 247: 55-59, (2013).

[18] Yang, C., Liu, Z., Zheng, Q., Cao, Y., Dai, X., Sun, L., Zhao, J., Xing, J., Han, Q., "Ultrasound assisted in-situ casting technique for synthesizing small-sized blocky Al3Ti particles reinforced A356 matrix composites with improved mechanical properties", Journal of Alloys and Compounds, 747: 580-590, (2018). 